\title{
CARACTERIZAÇÃO DA QUALIDADE DAS ÁGUAS SUPERFICIAIS DA MICROBACIA DO CÓRREGO DA ARARA EM SANDOVALINA - SP
}

\section{CHARACTERIZATION OF THE SURFACE WATER QUALITY OF THE CÓRREGO DA ARARA MICROBASIN IN SANDOVALINA-SP}

\author{
Noemi de Oliveira Dias ${ }^{1}$; Aline Targino da Silva ${ }^{2}$; Elson Mendonça \\ Felici $^{3}$; Nelissa Garcia Balarim ${ }^{3}$; Yeda Ruiz Maria ${ }^{3}$. \\ 1,2 Universidade do Oeste Paulista - UNOESTE, Curso de Engenharia Ambiental \\ e Sanitária, Presidente Prudente, SP. \\ E-mail:noemi_dias@outlook.com; aline_targino16@hotmail.com \\ ${ }^{3}$ Universidade do Oeste Paulista - UNOESTE, Docente do Curso de Engenharia \\ Ambiental e Sanitária, Presidente Prudente, SP. \\ E-mail: elson@unoeste.br
}

RESUMO - O presente estudo objetivou a caracterização da qualidade das águas superficiais da microbacia do Córrego da Arara localizada no município de Sandovalina - SP. Para o alcance do objetivo proposto, foram realizadas análises físico-químicas da água coletadas em quatro seções do córrego. Ao todo nove parâmetros foram analisados. Os resultados foram comparados aos valores determinados pela Resolução Conama $n^{\circ} 357 / 05$ para corpos hídricos classificados como Classe 2. Os valores obtidos para fósforo e $\mathrm{pH}$ mostraram que esses parâmetros estão em inconformidade com a resolução supracitada, sendo que, o pH apresentou valores abaixo e o fósforo apresentou acima dos estabelecidos pela resolução.

Palavras-chave: Microbacia hidrográfica; qualidade da água; parâmetros físico-químicos; Resolução Conama n³57/05; Córrego da Arara.

Recebido em: 27/08/2018 Aprovado em: 05/09/2018
ABSTRACT - The present study aimed to characterize the surface water quality of the Arara Stream microbasin located in the municipality of Sandovalina - SP. To reach the proposed objective, physical-chemical analyzes of the water collected in four sections of the stream were performed. In all nine parameters were analyzed. The results were compared to the values determined by Conama Resolution No. 357/05 for water bodies classified as Class 2 . The values obtained for phosphorus and $\mathrm{pH}$ showed that these parameters are in disagreement with the aforementioned resolution, and the $\mathrm{pH}$ has values below and phosphorus has concentrations above those set by resolution.

Keywords: Hydrographic microbasin; water quality; physical-chemical parameters; Conama Resolution No. 357/05; Arara Stream. 


\section{INTRODUÇÃO}

A água é um recurso natural abundante na natureza, isso é, quando se leva em consideração a quantidade desse recurso em todo o planeta independente de seu estado de matéria e suas características naturais. No entanto, quando se fala de água na sua forma líquida e doce, apropriada para o consumo humano e de outros seres vivos do planeta, essa quantidade diminui substancialmente. Estima-se que apenas 3\% do total da água existente no planeta seja água doce (OLIC, 2002).

Não obstante, essa quantidade de água apropriada para consumo pode ser ainda mais reduzida devido as alterações sofridas em sua qualidade, em consequência de ações antrópicas no meio aquático e uso indiscriminado desse recurso. Infelizmente, no cenário atual, é predominante o mau uso das águas, e isto vem causando a sua escassez relativa e a degradação de sua qualidade (NETTO et al., 2012).

No Córrego da Arara, localizado no município de Sandovalina - SP, essa degradação ambiental já é realidade. O mau uso do solo e o manejo inadequado da agricultura e pecuária no entorno do rio principal, aliado a falta de vegetação nas Áreas de Preservação Permanente (APP), vem ocasionando assoreamento, rebaixamento do volume das águas, poluição orgânica devido a presença de animais e escassez da fauna aquática. O ambiente aquático é um dos ecossistemas que mais sofre impactos causados pela ação antrópica, uma vez que constitui o compartimento final de vários produtos gerados pela atividade humana (AKAISHI, 2003).

A degradação acelerada dos recursos hídricos tem gerado debates e tem sido alvo da atenção de pesquisadores que buscam mitigar os efeitos negativos das ações antrópicas nos corpos hídricos. A água tem sido a centralizadora das atenções mundiais nos últimos anos, gerando diversas discussões sobre a utilização dos recursos hídricos, como: uma melhor gestão e uma melhor adequação desses recursos tão escassos (ARAÚJO et al., 2009).

As bacias e sub-bacias hidrográficas vêm se estabelecendo como área para planejamento e gestão dos recursos hídricos, pois a partir delas é possível elaborar planejamentos territoriais que evitem ou minimizem tanto os problemas sociais (decorrentes das enchentes, deslizamentos...), quanto os problemas ambientais (desmatamentos, poluição, aterros das nascentes, etc.) tão comuns nos dias atuais (Cysne, 2010 apud NOGUEIRA; COSTA; PERREIRA, 2015).

Existem muitos parâmetros por meio dos quais se avalia a qualidade das águas nos corpos hídricos, dentre elas as análises físicoquímicas que são amplamente utilizadas como parâmetros indicadores da qualidade. Uma normativa importante nesse contexto é a resolução CONAMA $n^{\circ}$ 357, de 17 de março de 2005. Pode-se, assim, comparar todos resultados das análises aos valores estabelecidos por essa legislação supracitada.

O monitoramento deve ser visto como um processo essencial à implantação dos instrumentos de gestão das águas, já que permite a obtenção de informações estratégicas, acompanhamentos das medidas efetivas, atualização do banco de dados e atualização das decisões. (MAGALHÃES JR, 2000).

Segundo Machado et al. (2012) a seleção dos parâmetros físico-químicos e biológicos de qualidade de água em um programa de monitoramento deverá levar em conta os usos previstos para o corpo d'água e as fontes de poluição existentes na sua área de drenagem. A combinação destes parâmetros possibilita a utilização de índices que podem representar a situação de determinado corpo d'água de forma confiável (DERÍsIO, 1992).

A Resolução №. 357, de 17 de março de 2005 do CONAMA, estabelece parâmetros que definem limites aceitáveis de elementos estranhos, considerando os diferentes usos (COLUNA et al., 2007). Os corpos d'água são classificados em 13 classes sendo cinco 
classes de água doce, com salinidade inferior a $0,5 \%$, quatro salobras, salinidade entre 0,5 e $30 \%$, e quatro classes salinas, salinidade superior a 30\% (BRASIL, 2005).

Diante do exposto, no presente estudo objetivou-se a avaliação da qualidade das águas superficiais da microbacia do Córrego da Arara, localizado no município de Sandovalina - SP, por meio de parâmetros físico-químicos. Os valores de cada parâmetro foram comparados aos estabelecidos na resolução CONAMA $n^{\circ}$ $357 / 2005$, para rios de Classe 2. Segundo a dados da Companhia Ambiental do Estado de São Paulo (CETESB), o Córrego da Arara se enquadra na Classe 2 (dois) na Classificação dos Recursos Hídricos dispostos na Resolução Conama no 357/2005.

\section{METODOLOGIA}

\subsection{Coleta e preservação das amostras}

Foram coletadas amostras de água em quatro pontos distintos do Córrego da Arara no dia 9 de abril de 2018 (Figura 1). A escolha desses pontos foi baseada em algumas características como a representatividade dos pontos de coleta, acessibilidade e segurança da amostragem.

Todas as amostras de água superficial foram coletadas em frascos devidamente limpos e preparados em uma profundidade de 15-30 centímetros. Após a coleta, as amostras foram identificadas e armazenadas para envio ao laboratório.

Os procedimentos de coleta e preservação de amostra foram realizados conforme as condições exigidas na normativa NBR 9898 de 30 junho de 1987 da Associação Brasileira de Normas Técnicas: Preservação e técnicas de amostragem de afluente líquidos e corpos receptores.
Figura 1. Pontos amostrados na microbacia do Córrego da Arara: Ponto 1 (a), Ponto (b), Ponto 3 (c) e Ponto 4 (d).

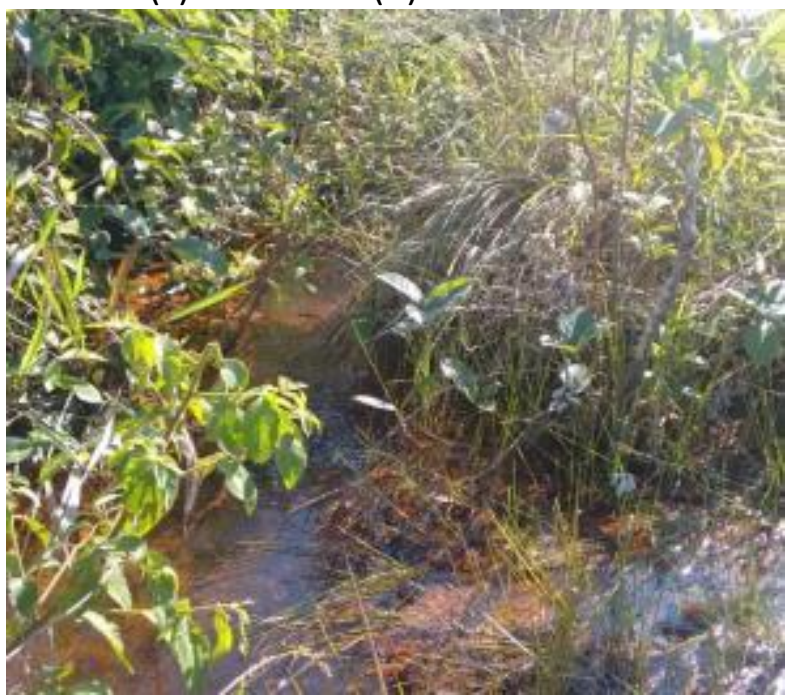

(a)

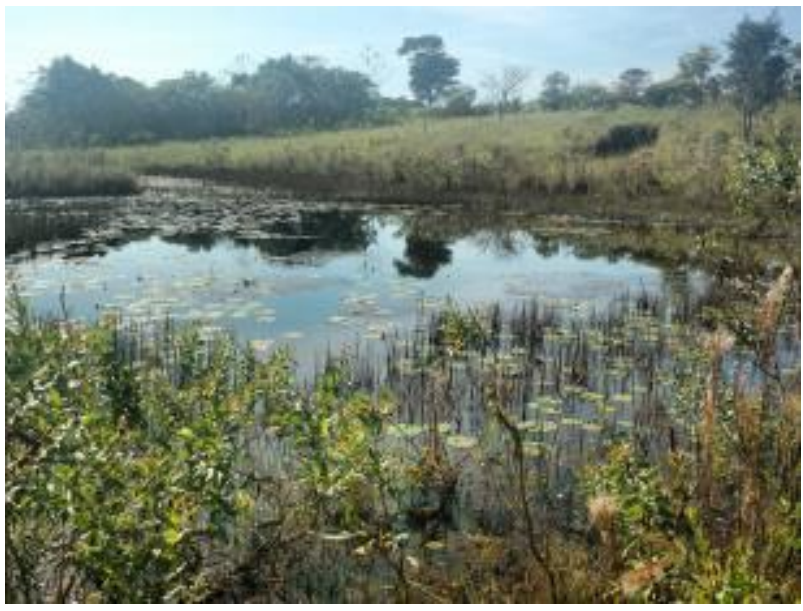

(b)

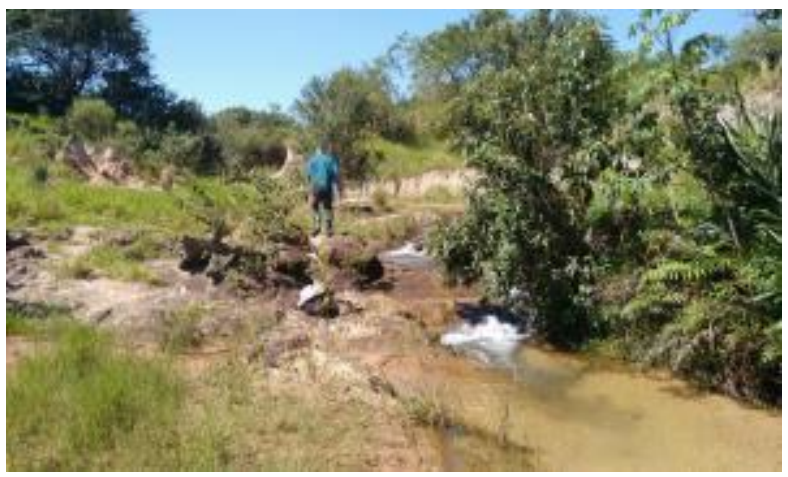

(c) 


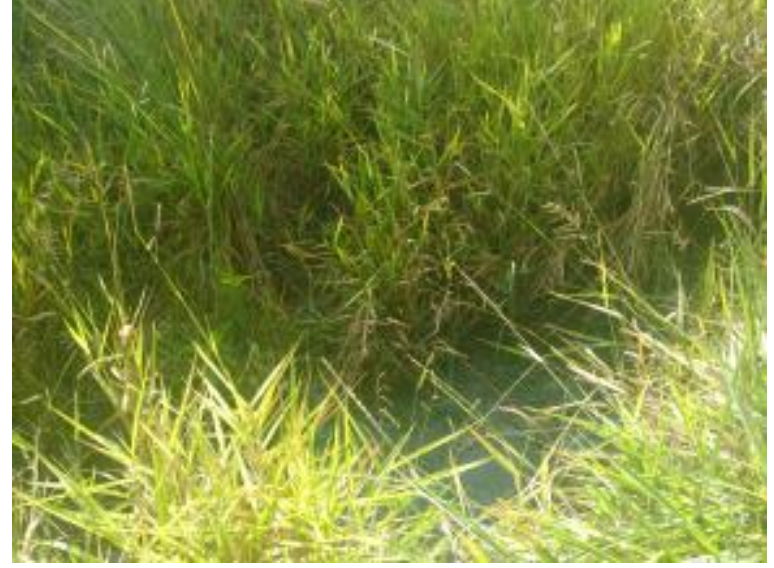

(d)

\subsection{Análises físico-químicas}

Para cada amostra coletada foram realizadas determinações de 9 parâmetros (Tabela 1): condutividade, demanda química de oxigênio (DQO), fósforo, nitrogênio, oxigênio dissolvido (OD), $\mathrm{pH}$, salinidade, temperatura e turbidez. Todos os procedimentos de análises foram realizados em conformidade com o Standard Methods for the Examination of Water and Wastewater (APHA, 2005).

Os resultados obtidos para os parâmetros foram comparados, quando existentes, com valores estabelecidos pela Resolução CONAMA n³57 de 17 de março de 2005. Todos valores obtidos nas análises físico-químicas foram sumarizados em tabela para melhor compreensão dos resultados. 
Tabela 1. Procedimentos utilizados para determinação dos parâmetros físico-químicos.

\begin{tabular}{|c|c|c|c|}
\hline PARÂMETROS & $\begin{array}{l}\text { DESCRIÇÃO DO } \\
\text { PROCEDIMENTO }\end{array}$ & PROCEDIMENTO & $\begin{array}{l}\text { DATA DA } \\
\text { ÁNALISE }\end{array}$ \\
\hline Condutividade & $\begin{array}{l}\text { Determinação da } \\
\text { condutividade por método } \\
\text { eletrométrico direto - } \\
\text { Condutimetria. }\end{array}$ & $\begin{array}{c}\text { (SMEWW 21a } \\
\text { Ed.,2005) - Método } \\
\text { 2510-A }\end{array}$ & $10 / 04 / 2018$ \\
\hline $\mathrm{pH}$ & $\begin{array}{l}\text { Determinação de pH por } \\
\text { método eletrométrico } \\
\text { direto - Potenciométrico }\end{array}$ & $\begin{array}{c}\text { (SMEWW 21á } \\
\text { Ed.,2005) - Método } \\
4500 \mathrm{H}+\mathrm{B}\end{array}$ & $10 / 04 / 2018$ \\
\hline Salinidade & $\begin{array}{l}\text { Determinação de Salinidade } \\
\text { por método condutimétrico. }\end{array}$ & $\begin{array}{c}\text { (SMEWW 21a } \\
\text { Ed.,2005) - Método } \\
\text { 2520-A }\end{array}$ & $10 / 04 / 2018$ \\
\hline $\begin{array}{l}\text { Oxigênio } \\
\text { Dissolvido }\end{array}$ & $\begin{array}{l}\text { Determinação de Oxigênio } \\
\text { Dissolvido por método } \\
\text { eletrométrico - Eletrodo de } \\
\text { membrana }\end{array}$ & $\begin{array}{c}\text { (SMEWW 21 a } \\
\text { Ed.,2005) - Método } \\
4500-0 \mathrm{~A}\end{array}$ & $10 / 04 / 2018$ \\
\hline Temperatura & $\begin{array}{c}\text { Determinação da } \\
\text { temperatura por método } \\
\text { eletrométrico - Termometro } \\
\text { de Mercúrio }\end{array}$ & $\begin{array}{c}\text { (SMEWW 21ạ } \\
\text { Ed.,2005) -Método } \\
2550-\text { B }\end{array}$ & $10 / 04 / 2018$ \\
\hline Turbidez & $\begin{array}{l}\text { Determinação da turbidez } \\
\text { por método nefelométrico }\end{array}$ & $\begin{array}{c}\text { (SMEWW 21a } \\
\text { Ed.,2005) -Método } \\
2130 \text { B }\end{array}$ & $10 / 04 / 2018$ \\
\hline DQO & $\begin{array}{l}\text { Determinação da Demanda } \\
\text { Química de Oxigênio (DQO) } \\
\text { por método Colorimétrico } \\
\text { por refluxo fechado }\end{array}$ & $\begin{array}{c}\text { (SMEWW 21ạ } \\
\text { Ed.,2005) -Método } \\
5220 \text { B }\end{array}$ & $16 / 04 / 2018$ \\
\hline Fósforo & $\begin{array}{l}\text { Determinação de Fósforo } \\
\text { por método colorimétrico } \\
\text { Ácido Ascórbico }\end{array}$ & $\begin{array}{l}\text { (SMEWW 21a } \\
\text { Ed.,2005) - Método } \\
4500 \text { P B e F }\end{array}$ & $23 / 04 / 2018$ \\
\hline Nitrato & $\begin{array}{l}\text { Determinação de Nitrato - } \\
\text { Método de Fenato }\end{array}$ & $\begin{array}{c}\text { (SMEWW 21a } \\
\text { Ed.,2005) - Método } \\
4500-\mathrm{NH3}-\mathrm{F}\end{array}$ & $07 / 05 / 2018$ \\
\hline
\end{tabular}

Fonte: Adaptado de SMEWW 21ạ Edição APHA (2005).

\section{RESULTADOS}

Os resultados das análises físicoquímicas seguem sumarizados na Tabela 2. Constatamos que os valores de Condutividade apresentaram uma pequena variação, embora não significativa, é notável um decréscimo no ponto 2 e um acréscimo no valor da condutividade do ponto 3 .

Os dados referentes a DQO se mantiveram constantes ao longo do perfil longitudinal do corpo d'água não apresentando variação visto que se mantêm em uma concentração inferior a $25 \mathrm{mg} / \mathrm{L}$ (Tabela 2).

A temperatura apresentou uma variação ao longo do perfil longitudinal do corpo d'água, no entanto, é possível notar que as temperaturas entre os pontos de amostragem foram bem próximas, com uma diferença nos valores do ponto 1 e ponto 4 de apenas $1,4^{\circ} \mathrm{C}$. Ao observar os dados para o Fósforo é possível notar que não houve variação significativa entre os valores desse parâmetro uma vez que o Fósforo se mantém 
em uma faixa pequena, de $0,1786 \mathrm{mg} / \mathrm{L} \mathrm{e}$ $0,15 \mathrm{mg} / \mathrm{L}$ (Tabela 2).

Os valores de nitrato não apresentaram variação significativa entre os pontos amostrados e se mantiveram em valores quase que constantes ao longo do percurso do rio. Os valores de $\mathrm{pH}$ não apresentaram drásticas variações ao longo do rio, os valores se mantiveram próximos em todos os pontos de amostragem, se mantendo em uma faixa de 5,53 a 6 (Tabela 2)..

Os dados referentes ao Oxigênio Dissolvido (OD) apresentaram pequena variação apresentando uma diferença entre os valores do ponto 1 e ponto 2 de 1,2 mg/L.

Os valores de Turbidez apresentaram variação significativa entre os pontos, é notável que o valor desse parâmetro tem um acréscimo de 1,62 NTU quando observado os valores do ponto 1 e ponto 2 e um decréscimo expressivo do ponto 2 ao ponto 4, uma variação de 4,32 NTU. Os valores de Salinidade não apresentaram nenhuma variação se mantiveram em $0 \mathrm{em}$ todo o perfil longitudinal do corpo d'água (Tabela 2).

Tabela 2. Dados físico-químicos do Córrego da Arara.

\begin{tabular}{l|c|c|c|c|c}
\hline Parâmetro & Legislação* & Ponto 1 & Ponto 2 & Ponto 3 & Ponto 4 \\
\hline Condutividade $(\mu \mathrm{S} \mathrm{cm}-1)$ & --- & 7,9 & 7,5 & 7,7 & 8,7 \\
\hline DQO (mg/L) & --- & $<25$ & $<25$ & $<25$ & $<25$ \\
\hline Temperatura ( $\left.{ }^{\circ} \mathrm{C}\right)$ & --- & 24 & 23,1 & 22,1 & 22,6 \\
\hline Fósforo (mg/L) & 0,1 & 0,1786 & 0,1532 & 0,1465 & 0,150 \\
\hline Nitrato (mg/L) & $\begin{array}{c}3,7 \text { mg/L para } \\
\text { pH }<\text { ou igual a } \\
7,5\end{array}$ & 1,1553 & 1,08 & 1,725 & 1,1235 \\
& 6 a 9 & 5,53 & 5,69 & 6,00 & 5,76 \\
\hline pH & $>5$ & 5,2 & 6,4 & 5,9 & 6,2 \\
OD (mg/L) & 0 & 0 & 0 & 0 & 0 \\
Salinidade (\%) & Até 100 & 4,46 & 6,08 & 2,56 & 1,76 \\
\hline
\end{tabular}

*Valores máximos permitidos para corpos hídricos classificados como Classe 2.

\section{DISCUSSÕES}

A condutividade não é um dos parâmetros estabelecidos pela Resolução Conama 357/05 para classificação de corpos hídricos. $\mathrm{E}$, no Brasil não existe nenhuma legislação que determine um limite desse parâmetro como aceitável. No entanto, Gasparotto (2011) afirma que para amostras contaminadas por esgotos domésticos, a condutividade pode variar de 100 a 10.000 $\mu \mathrm{S} / \mathrm{cm}$. Partindo dessa premissa, podemos considerar que os valores de condutividade são influenciados pelo grau de pureza da água. Desse modo, a partir dos valores para esse parâmetro a água do Córrego da Arara apresenta um grau de poluição baixíssima e a água é relativamente boa em todas as seções do rio, visto que, os valores para a condutividade ficaram entre 7,5 e $8,7 \mu \mathrm{S} / \mathrm{cm}$.

A temperatura, também, não tem um valor máximo permitido na resolução CONAMA $n^{\circ}$ 357/05. Segundo Nogueira, Costa e Pereira (2015), a diminuição na temperatura ao longo do perfil de um rio pode estar associada a fatores como a velocidade do escoamento do córrego ser mais baixa e a diminuição de incidência de raios solares motivado pela vegetação ciliar em algumas seções ser mais densa.

\section{A Resolução CONAMA 357/05} estabelece como limite aceitável de fósforo em um corpo d'água classificado como classe 2 uma concentração menor ou igual a 0,1 $\mathrm{mg} / \mathrm{L}$, e os valores obtidos nas análises desse parâmetro para o estudo de caso 
desenvolvido no córrego da Arara, embora não significativamente, foram superiores aos estabelecidos na resolução supracitada. Pellegrini (2005) afirma que o escoamento do solo de áreas agrícolas durante eventos pluviométricos é a principal fonte de poluição aos mananciais hídricos. Devido sua alta adsorção ao solo, o fósforo entra em corpos d'água superficiais adsorvidos às partículas de solos erodidos (MILLER; GARDINER, 1998 apud PELLEGRINI, 2005). Desse modo, a concentração de fósforo, mais elevada principalmente nos pontos 1 e 2 do Córrego da Arara, podem estar associadas a cultura de cana-de-açúcar existentes nas proximidades desses pontos.

As concentrações de Nitrato estão dentro dos limites estabelecidos pela legislação já que se mantém em uma faixa de 1,72 e $1,15 \mathrm{mg} / \mathrm{L}$ e os valores definidos na Resolução CONAMA 357/05 são de até 3,7 $\mathrm{mg} / \mathrm{L}$.

Os valores de $\mathrm{pH}$ mostraram incompatibilidade com a Resolução CONAMA $357 / 05$, pois os valores para esse parâmetro ficaram entre 5,53 e 6, e a legislação determina que para corpos d'água classificados como classe 2 devem apresentar pH entre 6 e 9. Segundo Magalhães Jr (2010) a acidez em uma amostragem pode ser decorrente da presença de ácidos húmicos e fúlvicos resultante da matéria orgânica presentes na água. Borges, Galbiatti e Ferraudo (2003) o tipo de solo onde a água percorre é outro fator que pode influenciar os valores de $\mathrm{pH}$ em um corpo d'água. Durante a coleta de amostras de água em todos os pontos, exceto no ponto 3 , foram identificadas grande quantidade de plantas aquáticas, suas raízes e folhas em decomposição podem estar alterando o $\mathrm{pH}$ da água deixando-a ácida.

Os valores de Oxigênio Dissolvido e Turbidez estão em conformidade com a Resolução. Sendo que os valores de OD, foram superiores a $5 \mathrm{mg} / \mathrm{L}$ e os valores de Turbidez se apresentaram abaixo de 100 NTU, assim como a resolução determina.

\section{CONSIDERAÇÕES FINAIS}

Nesse trabalho avaliamos a qualidade das águas superficiais da microbacia do Córrego da Arara, localizado no município de Sandovalina - SP, por meio de parâmetros físico-químicos. Com base nos valores dos parâmetros comparados com os da resolução CONAMA, $n^{\circ} 357 / 05$, concluímos que dos 5 parâmetros, o $\mathrm{pH}$ e fósforo estão em inconformidade com os valores estabelecidos para corpos hídricos classificados como classe 2. $\mathrm{O}$ pH está abaixo e o fósforo acima dos limites estabelecidos por essa resolução.

Concluímos, também, que ambos os parâmetros, o pH e o fósforo, estão sendo influenciados pela degradação ambiental em que a microbacia se encontra. Um resultado do mal planejamento e uso indiscriminado dos recursos naturais disponíveis nessa área.

Salientamos que a análise dos demais parâmetros listados na Resolução Conama $\mathrm{n}^{\circ}$ 357/05 requer um maior número de amostras, para garantia da confiabilidade dos resultados e efetividade do enquadramento do Córrego da Arara.

\section{AGRADECIMENTOS}

Agradecemos ao Daniel Ângelo Macena, técnico do laboratório de Química da Unoeste por todo suporte durante as análises laboratoriais.

\section{REFERÊNCIAS}

AKAISHI, F. M. Aplicação de bioindicadores de contaminação ambiental em estudos e monitoramento em campo. 2003. Dissertação (Mestrado em Morfologia) Universidade Federal do Paraná, Curitiba, PR, 2003.

APHA, AWWA, WEF. Standard Methods for the Examination of Water and Wastewater. 21. ed. Washington, 2005. 
ARAÚJO, L. E. et al. Bacias hidrográficas e impactos ambientais. Qualitas Revista Eletrônica, [S.I.], v. 8, n. 1, july 2009. doi: http://dx.doi.org/10.18391/qualitas.v8i1.399.

BRASIL. Ministério do Meio Ambiente. Conselho Nacional do Meio Ambiente. Resolução CONAMA No 357, de 17 de março de 2005. Disponível em: http://www.mma.gov.br/port/conama/res/ res05/res35705.pdf. Acesso em: 13 Ago. 2018.

BORGES, M. J.; GALBIATTI, J. A.; FERRAUDO, A. S. Monitoramento da qualidade hídrica e eficiência de interceptores de esgotos em cursos d' água urbanos da Bacia Hidrográfica do Córrego Jaboticabal. Revista Brasileira de Recursos Hídricos, v.8, n.2, p. 161-171, 2003.

DERÍSIO, J. C. Introdução ao controle de poluição ambiental. São Paulo: CETESB, 1992.

GASPAROTTO, F. A. Avaliação Ecotoxicológica e Microbiológica da água de nascentes urbanas no município de Piracicaba - SP. 2011. Dissertação (Mestrado em Biologia na Agricultura e no Ambiente) Centro de Energia Nuclear na Agricultura, Universidade de São Paulo, Piracicaba, 2011. doi:10.11606/D.64.2011.tde-06072011.

LOPES, F.W.A.; MAGALHÃES JR, A.P. Influência das Condições de $\mathrm{pH}$ sobre o índice de qualidade das águas (IQA) na bacia do Ribeirão de Carrancas. Revista Brasileira de Recursos Hídricos, Belo Horizonte, v.6, n.2, p. 134-147, 2007.

MACHADO, C. A.; FACCIOLI, G. G.; NETTO, A. O. A.; FOPPEL, E. F. C.; SILVA, M. G. Monitoramento da Qualidade da Água como ferramenta para gestão ambiental da Bacia Hidrográfica do Rio Siriri Vivo - Sergipe. Revista Educação Ambiental, n. 63, Ano. XVI. mar./jun. 2018. Disponível em: http://www.revistaea.org/artigo.php?idartig o=3111. Acesso em: 13 ago. 2018.

MAGALHÃES JR, A. P. A situação do monitoramento da águas no Brasil. Revista Brasileira de Recursos Hídricos, Belo Horizonte, v. 5, n. 3, p. 113-135, set. 2000.

https://doi.org/10.21168/rbrh.v5n3.p113135

NETTO, F. M. D. L.; SILVA, J. F.; RODRIGUES, S. C. Evolução da qualidade da água e uso do solo no período de julho de 2009 a junho de 2010 no Córrego Terra Branca Uberlândia - MG. Horizonte Cientifico, Uberlândia, v.6, n. 1, p. 1-20, ago. 2012.

NOGUEIRA, F. F.; COSTA, I. A.; PEREIRA, U. A. Análise de parâmetros físico-químicos da água e do uso e ocupação do solo na subbacia do Córrego da Água Branca no município de Nerópolis, Goiás. 2015. (Trabalho de conclusão de curso), Universidade federal de Goiás, Goiânia, 2015.

OLIC, N. B. A. A questão da água no Brasil. Revista Pangea Mundo, 2002.

PELLEGRINI, J. B. R. Fósforo na água e no sedimento na Microbacia Hidrográfica do Arroio Lino - Agudo- RS. 2005. Dissertação (Mestrado em Ciência do Solo) - Universidade Federal de Santa Maria, Santa Maria, RS, 2005. 